American Journal of Biochemistry and Biotechnology 3 (2): 55-59, 2007

ISSN 1553-3468

(C) 2007 Science Publications

\title{
Potential of Agarose for Biosorption of Cu(II) In Aqueous System
}

\author{
${ }^{1}$ Anurag Pandey, ${ }^{2}$ Debabrata Bera, ${ }^{1}$ Anupam Shukla and ${ }^{2}$ Lalitagauri Ray \\ ${ }^{1}$ Department of Biotechnology and Biomedical Engineering, National Institute of Technology, \\ Raipur- 492 010, India \\ ${ }^{2}$ Department of Food Technology and Biochemical Engineering, Jadavpur University, \\ Kolkata- 700 032, India
}

\begin{abstract}
The ability of agarose gel as an adsorbent for $\mathrm{Cu}(\mathrm{II})$ ions in aqueous solution was studied. The experiments were done as batch processes. Batch kinetics and isotherm studies were carried out under varying experimental conditions of contact time, $\mathrm{Cu}$ (II) ion concentration, adsorbent dose, temperature and $\mathrm{pH}$. Adsorption equilibrium of agarose gel was reached within $4 \mathrm{~h}$ for agarose gel when initial metal ion concentration was $25 \mathrm{mg} / \mathrm{l}$, while at higher concentration 175 $\mathrm{mg} / \mathrm{l}$ equilibrium was achieved in $6 \mathrm{~h}$. Kinetics of adsorption obeyed a pseudo second-order equation. The optimum sorbent loading was found to be $1 \%$ for $\mathrm{Cu}(\mathrm{II})$ removal. The biosorption of $\mathrm{Cu}$ (II) ions by agarose gel decreased as the initial concentration of metal ions increased in the medium. The maximum $\mathrm{Cu}(\mathrm{II})$ ions adsorbed was found to be $238 \mathrm{mg} / \mathrm{g}$ agarose gel. The maximum uptake of metal ions was obtained at $\mathrm{pH} 2.0$. At temperature $35^{\circ} \mathrm{C}$, the biosorption of metal ions was found to be highest, with increase or decrease in temperature resulted in a decrease in the metal ions uptake capacity. The suitability of the Langmuir and Freundlich adsorption models to the equilibrium data were investigated and it was found that the sorption data conformed well to Langmuir isotherm model. The studies showed that the agarose gel can be used as an efficient adsorbent biopolymer for removal of $\mathrm{Cu}(\mathrm{II})$ ions from water and wastewater.
\end{abstract}

Keywords: Biosorption, Agarose gel, Biopolymer, $\mathrm{Cu}(\mathrm{II})$ adsorption, Aqueous system

\section{INTRODUCTION}

The presence of toxic heavy metal contaminants in aqueous streams, arising from the discharge of untreated metal containing effluents into water bodies, is one of the most important environmental issues ${ }^{[1]}$. Discharge and treatment of industrial wastewater containing heavy metals and precise identification of the actual sources of heavy metal contamination of water resources is urgent, due to the acute, severe, and persistent impacts of these pollutants on human health and on the sustainability of ecosystems are important issues in environmental protection.

A variety of methods are used to remove these toxic substances from effluents and industrial wastewaters before discharging into natural water bodies. The main treatment technologies include precipitation, coagulation, ion-exchange, membrane processes and electrolytic technologies. However conventional treatment technologies like precipitation and coagulation become less effective and more expensive when situations involving high volumes and low metal concentrations are encountered and the application of membrane processes and activated carbon are also restricted due to high costs ${ }^{[2]}$. As a result, cost-effective alternate technologies involving removal of heavy metals from wastewater are being sought to meet discharge standard.

Biological methods for remediation may provide the alternative ${ }^{[3-5]}$. Biosorption have been recommended as cheaper and most effective techniques ${ }^{[6]}$. Among the various biological systems, dead systems offer many advantages over live systems because they do not fall prey to toxicological effects of high concentrations of contaminants and can be obtained inexpensively ${ }^{[7]}$. Biopolymers are non-toxic, selective, efficient and inexpensive, and

Corresponding Author: Anurag Pandey, Department of Biotechnology and Biomedical Engineering, National Institute of Technology, Raipur- 492010 India 
thus highly competitive with ion exchange resins and activated carbon ${ }^{[8]}$.

The aim of this study was to explore the possibility using agarose gel for removing $\mathrm{Cu}(\mathrm{II})$ ions from aqueous solution. The influence of various factors, such as adsorbent loadings, initial $\mathrm{pH}$, temperature and initial metal ion concentrations on the sorption capacity were studied. The Langmuir and Freundlich models were used to analyze the adsorption equilibrium.

\section{MATERIALS AND METHODS}

Preparation of agarose gel: A desired amount of agarose gel was prepared by dissolving agarose in distilled water and keeping in a boiling water bath, and then plated into petri plates. The resultant polymerized gel was cut into pieces of approximately $3 \times 3 \mathrm{~mm}^{2}$ sizes.

Metal solutions: Metal stock solutions containing $\mathrm{Cu}$ (II) with a concentration of $1000 \mathrm{mg} / \mathrm{l}$ were prepared using deionized distilled water and salts containing the metals. For biosorption experiments, concentrations ranging from 25-200 $\mathrm{mg} / \mathrm{l}$ were prepared and $\mathrm{pH}$ of the metal solutions was adjusted to desired value using $0.1 \mathrm{M}$ citrate buffer.

Apparatus and glassware: All metal uptake experiments were carried out using $250 \mathrm{ml}$ Erlenmeyer flasks. Metal ion concentrations were determined using Varian spectra A-220 atomic absorption spectrophotometer.

Biosorption studies: Biosorption experiments were carried out in $250 \mathrm{ml}$ Erlenmeyer flasks by agitating pre-weighed amount of adsorbent with $50 \mathrm{ml}$ of aqueous metal ion solution, in order to find out the optimum adsorbent loading, for a pre determined time interval at $150 \mathrm{rpm}$ speed using a rotary shaker. The effect of $\mathrm{pH}$ of the suspending medium on metal removal was studied by performing equilibrium sorption tests at different $\mathrm{pH}$ values ranging from $\mathrm{pH}$ 1.0 and 4.0. In order to determine the effect of temperature variation on metal ion uptake by agarose gel, the temperature of the reaction was varied from $20^{\circ} \mathrm{C}$ to $40^{\circ} \mathrm{C}$. After adsorption, the mixture was filtered through Whatman No-1 filter paper. Residual concentration of metal ion present in the clear supernatant was estimated. The amount of metal bound was taken to be the difference between the initial and final metal concentration. For isotherm analysis, adsorption experiments were conducted by varying the initial metal ion concentration from 25 $200 \mathrm{mg} / \mathrm{l}$ and equilibrated for $6 \mathrm{~h}$.

\section{RESULTS AND DISCUSSION}

Biosorption kinetic studies: Pseudo second-order equation was employed to model the sorption data over the entire time range. The pseudo second-order kinetic rate equation of Lagergren is generally expressed as follows ${ }^{[9]}$ :

$d q / \mathrm{d} t=k_{2}\left(q_{e}-q\right)^{2}$

Where $k_{2}$ is the pseudo second order rate constant $(\mathrm{g} / \mathrm{mg} / \mathrm{min})$. Integrating and applying boundary conditions as $t=0$ and $q=0$ to $t=t$ and $q=q_{\mathrm{e}}$, Eq. (1) becomes

$t / q=1 / q_{\mathrm{e}}{ }^{2} k_{2}+t / q_{\mathrm{e}}$

The rate constant $k_{2}$ can be obtained from the intercept of the linearized pseudo second-order rate equation. If the pseudo second-order rate equation can fit the sorption data, there should be good linearity between $t / q_{t}$ and $t$.

Fig.1 shows that the pseudo second-order equation was applicable to all the sorption data $\left(R^{2}=\right.$ 0.9972), straight line obtained indicating that the process follows pseudo second-order kinetics, and $k_{2}$ value is $1.2 \mathrm{~g} / \mathrm{mg} / \mathrm{min}$. This confirms that there is more than one mechanism involved in the adsorption process.

Effect of amount of sorbent on biosorption: The amount of adsorbent on the efficiency of adsorption was also studied. The results of biosorption experiments obtained by using gels with varying agarose load with $1-3 \%(\mathrm{w} / \mathrm{v})$ are listed in Table 1.

Table 1: Biosorption capacity of agarose gel for $\mathrm{Cu}(\mathrm{II})$ at varying sorbent dose; $50 \mathrm{ml}$ Single metal solution $(50 \mathrm{mg} / \mathrm{l})$ of $\mathrm{Cu}(\mathrm{II})$ was contacted with 1-3\% w/v of agarose for $6 \mathrm{~h}$ at $\mathrm{pH} 2.0$ and temperature $35^{\circ} \mathrm{C}$

\begin{tabular}{lc}
\hline Agarose dose \% (w/v) & \% removal of Cu(II) ions \\
\hline 1 & 64 \\
2 & 58 \\
3 & 64 \\
\hline
\end{tabular}

It was observed that $1 \%$ agarose concentration, was found to be optimum for $\mathrm{Cu}$ (II) removal. This can be attributed to the difference in porosity of the gels when a higher quantity of sorbent was loaded. The 
Table 2: Langmuir and Freundlich isotherm constants

\begin{tabular}{ccccccc}
\hline & \multicolumn{3}{c}{ Langmuir isotherm } & \multicolumn{3}{c}{ Freundlich isotherm } \\
\hline Type of Adsorbent & $\mathrm{q}_{\max }(\mathrm{mg} / \mathrm{g})$ & $\mathrm{b}(\mathrm{L} / \mathrm{mg})$ & $\mathrm{r}^{2}$ & $\mathrm{~K}_{\mathrm{F}}$ & $\mathrm{n}$ & $\mathrm{r}^{2}$ \\
Agarose & 238 & 0.0050 & 0.9668 & 1.1 & 1.0 & 0.9420 \\
\hline
\end{tabular}

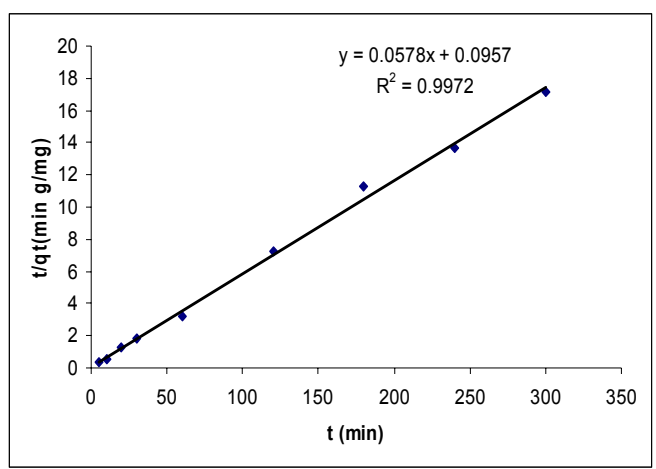

Fig. 1: Plot of $t / q_{t}$ and $t$

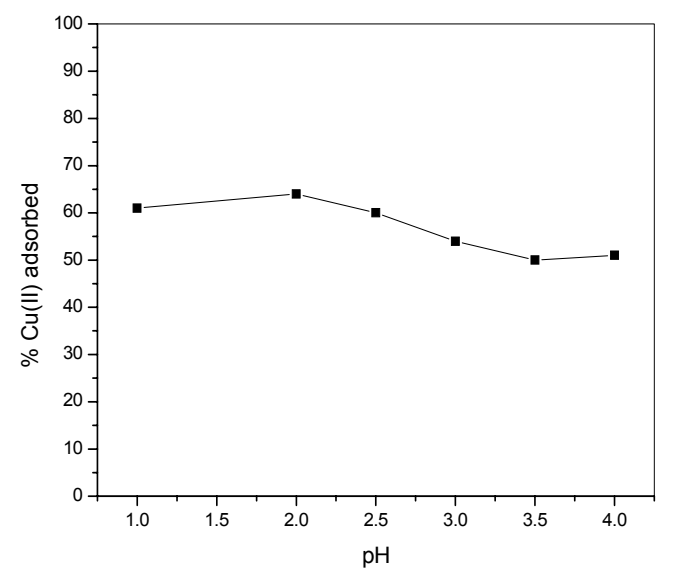

Fig. 2. Effect of $\mathrm{pH}$ on metal uptake by agarose gel; $50 \mathrm{ml}$ Single metal solution $(50 \mathrm{mg} / \mathrm{l})$ of $\mathrm{Cu}(\mathrm{II})$ was contacted with $1 \%$ of agarose for $6 \mathrm{~h}$, temperature $35^{\circ} \mathrm{C}$

increase in dose of sorbent in relation to amount reduced the surface area of the gels ${ }^{[10]}$. As the sorbent dose was increased, the gels became less porous and the free transport of metal ions to the interior adsorption sites was affected. Because of the reduced porous nature, the total surface area of entrapped biosorbent particle, interacting with metal ions is reduced.

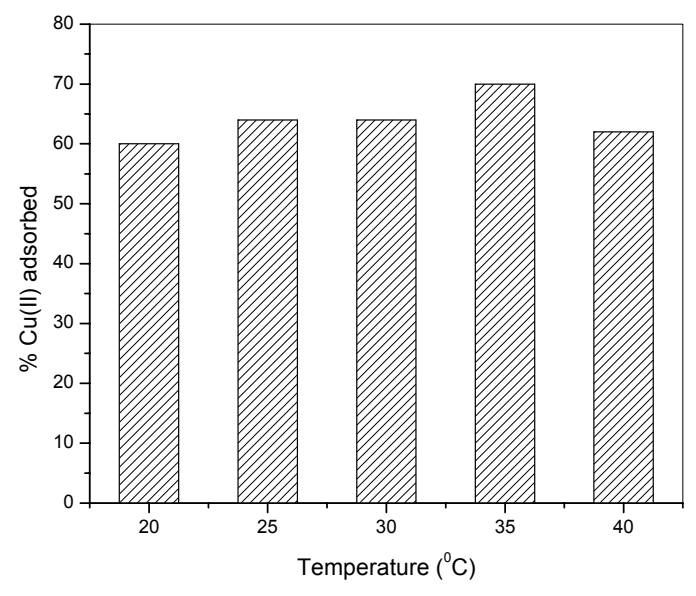

Fig. 3. Effect of temperature on metal biosorption of $\mathrm{Cu}(\mathrm{II})$ by agarose gel; $50 \mathrm{ml}$ Single metal solution $(50 \mathrm{mg} / \mathrm{l})$ of $\mathrm{Cu}(\mathrm{II})$ was contacted with $1 \%$ of agarose gel for $6 \mathrm{~h}$ at $\mathrm{pH} 2$

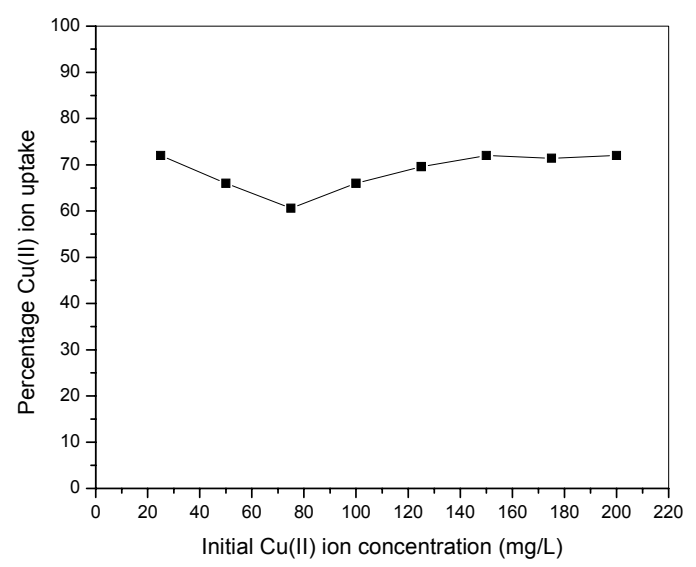

Fig. 4. Effect of initial metal ion concentration on biosorption of $\mathrm{Cu}$ (II) by agarose gel; $50 \mathrm{ml}$ Single metal solution $(25-200 \mathrm{mg} / \mathrm{l})$ of $\mathrm{Cu}$ (II) was contacted with $1 \%$ of agarose gel for $6 \mathrm{~h}$ at $\mathrm{pH} 2$ and temperature $35^{\circ} \mathrm{C}$ 


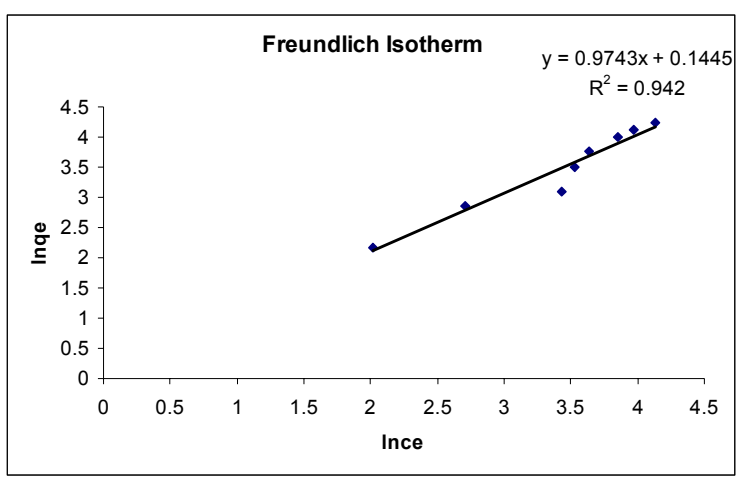

Fig.5: Freundlich adsorption isotherms for $\mathrm{Cu}(\mathrm{II})$ biosorption by agarose gel, metal ion concentration range $25-200 \mathrm{mg} / \mathrm{l}$, contact time $6 \mathrm{~h}$ at $\mathrm{pH} 2.0$ and temperature $35^{\circ} \mathrm{C}$

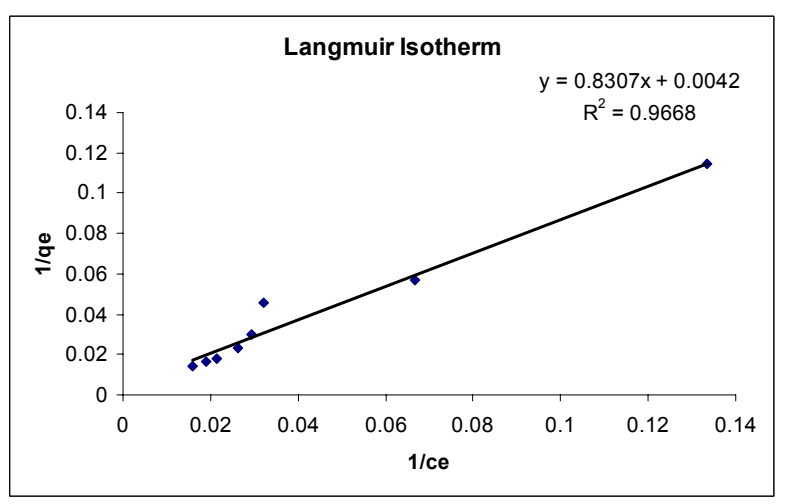

Fig. 6: Langmuir adsorption isotherms for $\mathrm{Cu}(\mathrm{II})$ biosorption by agarose gel, metal ion concentration range $25-200 \mathrm{mg} / \mathrm{l}$, contact time $6 \mathrm{~h}$ at $\mathrm{pH} 2.0$ and temperature $35^{\circ} \mathrm{C}$

Effect of initial pH: The adsorption of $\mathrm{Cu}$ (II) from aqueous solution is dependent on the $\mathrm{pH}$ of the solution, which affects the surface charge of the adsorbent. It was therefore important to study the effect of $\mathrm{pH}$ on the adsorption of $\mathrm{Cu}$ (II). The effect of the $\mathrm{pH}$ of the suspending medium on metal removal was studied by performing equilibrium sorption tests at different $\mathrm{pH}$ values ranges from $\mathrm{pH}$ 1-4. Adjustments to $\mathrm{pH}$ were made with $0.1 \mathrm{M}$ citrate buffer. Metal uptake was affected by $\mathrm{pH}$ of the metal solution (Fig. 2). It is clear that maximum adsorption of $\mathrm{Cu}$ (II) occurred at $\mathrm{pH} 2$, and decreased at lower and higher $\mathrm{pH}$. Metal uptake by agarose gel decreases as the $\mathrm{pH}$ increases and the maximum removal for $\mathrm{Cu}(\mathrm{II})$ ions was $64 \%$ at $\mathrm{pH} 2.0$.
Effect of temperature: Results of metal sorption experiments carried out in order to determine the optimum reaction temperature for $\mathrm{Cu}$ (II) adsorption by agarose gel in solution, the metal sorption experiments was carried out at different temperatures ranging from $20^{\circ} \mathrm{C}$ to $40^{\circ} \mathrm{C}$, when the amount of adsorbent in gel, $\mathrm{pH}$ and initial $\mathrm{Cu}(\mathrm{II})$ concentration were $0.1 \mathrm{~g}, 2.0$ and $50 \mathrm{mg} / \mathrm{l}$, using $50 \mathrm{ml}$ solution in $250 \mathrm{ml}$ Erlenmeyer flask are shown in Fig.3. It was observed that the extent of sorption of metal ions by the sorbent increased with increase in temperature upto $35^{\circ} \mathrm{C}$. Further increase in the temperature of the reaction mixture showed reduction in biosorption. It has been suggested that increase in metal uptake at increased temperature is due to either higher affinity of sites for metal or an increase in binding sites on relevant biosorbent ${ }^{[11]}$.

Effect of initial metal ion concentration: The metal removal by agarose gels corresponding to different initial metal concentrations (25, $50,75,100,125,150,175,200 \mathrm{mg} / \mathrm{l})$ are shown in Fig. 4. The parameters such as reaction temperature was fixed at $35^{\circ} \mathrm{C}$ and $\mathrm{pH}$ was adjusted at 2.0 , where as the amount of sorbent in gels were $1 \%$ are kept constant in $50 \mathrm{ml}$ solution containing $\mathrm{Cu}$ (II) ions in $250 \mathrm{ml}$ Erlenmeyer flask. As can be seen from Fig. 4, removal of $\mathrm{Cu}$ (II) ions is $70 \%$ at $25 \mathrm{mg} / 1$ concentration of $\mathrm{Cu}$ (II) ions in aqueous solution. The binding sites are limited keeping agarose loadings as constant. With increasing metal concentration, the percentage of metal removed was decreased to 125 $\mathrm{mg} / \mathrm{l}$ and then stabilized with further increment in the metal concentration upto $200 \mathrm{mg} / \mathrm{l}$. This could be because at higher concentrations, as more ions are competing for the available binding sites, the rate of adsorption decreased, resulting in lower adsorption percentage.

Analysis of adsorption isotherms: Analysis of equilibrium data is essential to develop an equation which precisely represents the results and which can be used for design purposes. Various isotherm models have been used for the equilibrium modelling of biosorption systems. The most widely used isotherm models to describe the biosorption process are Langmuir and Freundlich model.

The Langmuir isotherm assumes monolayer adsorption, and is presented by the following equation:

$q_{\mathrm{e}}=q_{\mathrm{max}} b C_{\mathrm{eq}} /\left(1+b C_{\mathrm{eq}}\right)$

Where $q_{\mathrm{e}}$ and $q_{\mathrm{max}}$ are the observed uptake capacity at equilibrium and maximum uptake capacities $(\mathrm{mg} / \mathrm{g}$ biosorbent), $C_{\mathrm{eq}}$ is the equilibrium concentration $(\mathrm{mg} / \mathrm{l}$ solution); $b$ is the equilibrium constant $(1 / \mathrm{mg})$. 
The linearized form of this equation is as

$1 / q_{\mathrm{e}}=1 / q_{\mathrm{m}} b \cdot 1 / C_{\mathrm{e}}+1 / q_{\mathrm{m}}$

$1 / q_{\mathrm{e}}$ vs $1 / C_{\mathrm{e}}$ gives the straight line with slope $1 / q_{\mathrm{m}} b$ and $1 / q_{\mathrm{m}}$ as intercept. $b$ is the sorption isotherm constant $(1 / \mathrm{mg})$.

The Freundlich isotherm equation is an empirical equation based on the sorption on a heterogeneous surface suggesting that binding sites are not equivalent and /or independent. The monocomponent Freundlich isotherm equation ${ }^{[5]}$ is given below:

$q_{\mathrm{e}}=K_{\mathrm{f}} C_{\mathrm{e}}{ }^{1 / n}$

where $K_{\mathrm{f}}$ is the Fruendlich isotherm constant, related to sorption capacity; $n$ is the constant related to affinity of the metal ions on adsorbent.

A logarithmic plot linearized the equation

$\ln q_{\mathrm{e}}=\ln K_{\mathrm{f}}+1 / n \ln C_{\mathrm{e}}$

Where, $q_{\mathrm{e}}$ the amount of metal ions adsorbed per unit mass of adsorbent at equilibrium, $\mathrm{mg} / \mathrm{g}, C_{\mathrm{e}}$ equilibrium concentration of aqueous solution, $\mathrm{mg} / \mathrm{l}$, $K_{\mathrm{f}}$ constant related to adsorption capacity, $1 / n$ constant related to adsorption intensity.

$\ln q_{\mathrm{e}}$ vs $\ln C_{\mathrm{e}}$ gives the straight line with slope $1 / n$ and $\ln K_{\mathrm{f}}$ as intercept.

It can be observed from Fig. 5 and 6 that both Freundlich and Langmuir isotherms model exhibited good fit to the sorption data of $\mathrm{Cu}(\mathrm{II})$. From Table- 2, it is concluded that the Langmuir isotherm model is slight better than Fruendlich isotherm model to fit $\mathrm{Cu}(\mathrm{II})$ sorption data well cover a concentration range $25 \mathrm{mg} / \mathrm{l}$ to $200 \mathrm{mg} / \mathrm{l}$. Fig-5, shows the linear plot of $\operatorname{lnq}_{\mathrm{e}}$ versus $\ln \mathrm{C}_{\mathrm{e}}$ giving a straight line $\left(\mathrm{r}^{2}=\right.$ 0.9420 ) and Fig-6, shows the linear plot of $1 / \mathrm{q}_{\mathrm{e}}$ versus $1 / C_{e}$ giving a straight line $\left(r^{2}=0.9668\right)$, with slope $1 / n$ and intercept lnk and the characteristic parameters $\mathrm{q}_{\max }$ and $\mathrm{b}$ for Freundlich and Langmuir isotherm respectively. The values of the Langmuir and Freundlich constants are presented in Table-2, for the agarose gel adsorption system.

\section{CONCLUSION}

The results demonstrate the agarose gel can be successfully used as a biosorbing agent for the removal of heavy metal ions from aqueous solution. The characterization of $\mathrm{Cu}$ (II) uptake by agarose gel showed that the binding kinetics was found to be dependent on experimental conditions, particularly the medium $\mathrm{pH}$, temperature and the initial concentration of metal ions. The Freundlich and Langmuir adsorption models was used to represent the experimental data and equilibrium data fitted very well to both the Freundlich and Langmuir isotherm model. The Langmuir isotherm represented the equilibrium data slightly better than Freundlich isotherm well cover a concentration range $25 \mathrm{mg} / \mathrm{l}$ to
$200 \mathrm{mg} / \mathrm{l}$. These studies show that agarose gel can be used as a filler material to build a permeable barrier to intercept the flow of groundwater. Heavy metal ions in the water will be adsorbed by the biopolymer and water passing through the barrier will free of metal ions.

\section{REFERENCES:}

1. Sudha Bai, R. and T. Emilia Abraham, 2003. "Studies on chromium(VI) adsorption-desorption using immobilized fungal biomass. Bioresource Technology, 87: 17-26.

2. Kapoor, A. and T. Viraraghavan, 1995. Fungal biosorption an alternative treatment option for heavy metal cleaning wastewaters: a review. Bioresource Technology, 53 : 195-206.

3. Tan, H., J.T. Champion, J.F. Artiola, M.L. Brusscan and R.M. Miller, 1994. Complexation of $\mathrm{Cd}$ by Rhamnolipid biosurfactant. Environ. Sci. Technol., 28: 2402-2406.

4. Chandra Shekhar, K., K.A. Natrajan, S. Subramanium and J.M. Modak, 1998. Removal of metal ions using an industrial biomass with reference to environmental control. Int. J. Miner. Process, 53:107-120.

5. Jalali R., H. Ghafourian, Y. Asef, S.J. Davarpanah and S. Sepehr, 2002. Removal and recovery of lead using nonliving biomass of marine algae. J. Hazard. Mater., 92: 253-262.

6. Bolton, H. and C.P. Huang, 1996. Application of Aspergillus oryzae and Rhizopus oryzae for $\mathrm{Cu}(\mathrm{II})$ removal. Water Res., 30: 1985-90.

7. Kratochvil, D. and B. Volesky, 1997. Advances in biosorption of heavy metals. Trends Biotechnol., 16: 291-300.

8. Wilde, E.W. and J.R. Benemann, 1993.Bioremoval of heavy metals by the use of microalgae. Biotechnology Advances, 11: 781782.

9. Ho, Y.S. and G. McKay, 1999. Pseudo-second order model for sorption processes. Process Biochem., 34: 451-65 .

10. Spiniti, M., H. Zhuang and E.M. Trujillo, 1995. Evaluation of immobilized biomass beads for removing heavy metals from wastewater. Water Environ. Res., 67:943-952.

11. Marques, A.M., X. Roca, M.D. Simon-Pujol, M.C. Fuste and F. Congregado, 1991. Uranium accumulation by Pseudomonas sp.EPS-5028. Applied Microbiology and Biotechnology, $35: 406-410$ 